\title{
KEBERADAAN BURUNG RANGKONG (Bucerotidae) DI GUNUNG BETUNG TAMAN HUTAN RAYA WAN ABDUL RACHMAN
}

\section{(THE EXISTANCE OF HORNBILLS (Bucerotidae) IN BETUNG MOUNTAIN OF TAMAN HUTAN RAYA WAN ABDUL RACHMAN)}

\author{
Andry Setyawan Aryanto ${ }^{1)}$, Agus Setiawan'), dan Jani Master ${ }^{2)}$ \\ 1) Jurusan Kehutanan Fakultas Pertanian Universitas Lampung, \\ 2) Jurusan Biologi Fakultas Matematika dan Ilmu Pengetahuan Alam Universitas Lampung, \\ Jl. Soemantri Brojonegoro No. 1 Bandar Lampung \\ Email : andryandroy@yahoo.com Phone : 085789121432
}

\begin{abstract}
ABSTRAK
Seluruh jenis rangkong (Bucerotidae) di Indonesia merupakan satwa yang dilindungi melalui Undang-undang No. 5 tahun 1990 tentang Konservasi Sumber Daya Alam Hayati dan Ekosistemnya dan Peraturan Pemerintah No. 7 Tahun 1999 tentang Pengawetan Tumbuhan dan Satwa. Salah satu kawasan yang teridentifikasi sebagai habitat rangkong di Sumatera adalah Gunung Betung Taman Hutan Raya Wan Abdul Rachman (Tahura WAR). Penelitian ini bertujuan untuk memberikan informasi tentang keberadaan burung rangkong dan habitatnya di Gunung Betung Tahura WAR. Penelitian dilaksanakan pada Mei 2015 dengan menggunakan metode jelajah dan area terkonsentrasi. Hasil penelitian menunjukkan bahwa di Gunung Betung terdapat satu jenis rangkong yang teramati baik secara visual maupun audio, yakni rangkong badak (Buceros rhinoceros). Burung rangkong sering ditemui di daerah yang terjal dengan pohon-pohon yang tinggi $(>17 \mathrm{~m})$ dan berdiameter besar $(>30 \mathrm{~cm})$, beraktivitas pada pohon Ficus dan Litsea sp. Pohon-pohon tersebut dimanfaatkan sebagai tempat mencari makan, bertengger, berlindung dan bersarang bagi burung rangkong. Ancaman dan gangguan terhadap burung rangkong dan habitatnya yakni perusakan hutan dan perluasan tanaman perkebunan kopi, kakao dan karet.
\end{abstract}

Kata kunci : habitat, Burung Rangkong, Tahura WAR

\section{ABSTRACT}

All species of hornbill (Bucerotidae) in Indonesia are protected by Law No. 5 of 1990 about Conservation of Natural Resources and Ecosystems and Government Regulation No. 7 of 1999 about Preservation of Plants and Animals. One of area that was identified as hornbill habitation in Sumatra is Betung Mount Tahura Wan Abdul Rachman (Tahura WAR). The aims of this research are to provide the information of hornbill existence and their habitation in Betung Mount Tahura WAR. This research was conducted in May 2015 used the exploration method and concentrated area. The results showed at Betung Mount there is one species of hornbill that was observed both visually and audio, its rhinoceros hornbill (Buceros rhinoceros). Hornbill often found in steep areas and trees with high (>17 m) and diameter large (>30 cm), hornbill did their activity in the Ficus and Litsea sp tree. The trees are used as foraging, roosting, shelter and nesting for hornbills. Threats and interferences of hornbills and their habitation caused of deforestation and land expansion of coffee, cocoa and rubber plantations.

Keywords: habitation, Hornbill, Tahura WAR 


\section{PENDAHULUAN}

Seluruh jenis rangkong (Bucerotidae) di Indonesia merupakan satwa yang dilindungi melalui Undang-undang No. 5 tahun 1990 tentang Konservasi Sumber Daya Alam Hayati dan Ekosistemnya dan Peraturan Pemerintah No. 7 Tahun 1999 tentang Pengawetan Tumbuhan dan Satwa. Rangkong merupakan kelompok burung yang mudah dikenali. Secara umum ciri yang dimiliki burung rangkong adalah ukuran tubuhnya yang besar dengan panjang total antara 381 sampai $1600 \mathrm{~mm}$. Memiliki paruh yang sangat besar dan kokoh tetapi ringan yang dinamakan hornbilll, berwarna merah atau kuning, melengkung dan beberapa menyerupai cula. Bulu berwarna coklat, hitam, putih, atau hitam dan putih. Kulit dan bulu disekitar tenggorokan berwarna terang, sayap kuat, ekor panjang, kaki pendek, jari-jari kaki besar dan sindaktil (MacKinnon, Philipps dan Balen, 2010).

Indonesia memiliki 13 spesies burung rangkong. Spesies tersebut tersebar di lima pulau besar, yaitu di Sumatera, Jawa, Kalimantan, Sulawesi, dan Irian Jaya (Sukmantoro, Irham, Novarino, Hasudungan, Kemp dan Muchtar, 2007). Salah satu kawasan yang yang teridentifikasi sebagai habitat burung rangkong di Sumatera adalah di Gunung Betung Taman Hutan Raya Wan Abdul Rachman (Tahura WAR). Hutan alami pada Gunung Betung menjadi habitat penting bagi keberadaan burung rangkong di Tahura WAR. Akan tetapi, dengan meningkatnya pembukaan hutan menjadi perkebunan dan pertanian, mengakibatkan semakin berkurangnya habitat bagi satwa terutama burung rangkong.

Penelitian tentang keberadaan burung rangkong di Gunung Betung Tahura WAR masih sedikit dilakukan sehingga informasi terbaru tentang keberadaan burung rangkong di lokasi tersebut masih terbatas. Penelitian ini dimaksudkan untuk memberikan informasi terbaru tentang keberadaan burung rangkong dan habitatnya serta ancaman yang dihadapi oleh burung tersebut di Gunung Betung Tahura WAR.

Tujuan dari penelitian ini adalah mengetahui keberadaan burung rangkong ketersediaan pohon pakan dan potensi pohon sarang serta ancaman yang dihadapi burung tersebut di Gunung Betung Tahura WAR. Manfaat yang diharapkan dari penelitian ini adalah memberikan data dan informasi bagi UPTD Tahura WAR serta pihak terkait lainnya dalam upaya pelestarian burung rangkong dan sebagai refrensi untuk pengembangan penelitian lebih lanjut.

\section{METODE PENELITIAN}

Penelitian keberadaan rangkong dilaksanakan di Gunung Betung Taman Hutan Raya Wan Abdul Rachman. Waktu penelitian Mei 2015. Alat yang digunakan dalam penelitian adalah teropong binokular, kamera digital, jam tangan, buku panduan lapangan Burung di Sumatera, Jawa, Bali, dan Kalimantan, haga meter, pita meter, tally sheet, alat tulis kantor, GPS (Global Positioning System) dan peta wilayah. Objek yang diamati adalah burung rangkong dan pohon yang berpotensi sebagai pohon sarang dan sumber pakan yang ada di Gunung Betung Tahura WAR.

Pengamatan dilakukan selama 14 hari pada pagi (07.00-09.00), siang (11.00-13.00) dan sore (15.00-17.00). Objek penelitian adalah burung rangkong yang ada di Gunung Betung Tahura WAR Blok Pendidikan 23 dan 24. Mengamati pohon yang berpotensi menjadi sumber pakan dan potensi pohon sarang di sekitar lokasi penelitian.

Pengumpulan data keberadaan jenis rangkong dilakukan dengan menggunakan metode area terkonsentrasi yang ditentukan dengan observasi lapang dan informasi dari masyarakat mengenai lokasi yang sering di temukan burung rangkong. Data yang diambil yaitu nama jenis rangkong, waktu perjumpaan, jumlah individu, jenis perjumpaan (visual/audio) dan lokasi perjumpaan. Pengumpulan data untuk potensi pohon sarang dan ketersedian pohon 
pakan dilakukan dengan menggunakan metode Rapid assessment di sekitar daerah pengamatan.

Analisis data pada penelitian ini yaitu menggunakan analisis deskriptif kualitatif, yaitu peneliti menguraikan, menjelaskan dan menggambarkan hasil data yang didapat di lapangan dan disusun dalam bentuk kalimat ilmiah secara sistematis.

\section{HASIL DAN PEMBAHASAN}

\section{A. Lokasi Keberadaan Burung Rangkong}

Bedasarkan hasil observasi dengan menggunakan metode jelajah dan wawancara dengan masyarakat berhasil ditemukan tiga titik pengamatan yaitu titik pengamatan 1 pada koordinat S $5^{\circ} 25^{\prime} 26,3^{\prime \prime}$ E $105^{\circ} 09^{\prime} 31,8^{\prime}$ " di ketinggian $1036 \mathrm{~m}$ dpl, titik pengamatan 2 pada koordinat S $5^{\circ} 25^{\prime} 32,5^{\prime}$ ' E $105^{\circ} 09^{\prime} 27,8^{\prime \prime}$ di ketinggian $1067 \mathrm{~m}$ dpl dan titik pengamatan 3 pada koordinat S $5^{\circ} 25^{\prime} 39,5^{\prime \prime}$ E $105^{\circ} 09^{\prime} 21,2$ " di ketinggian $1171 \mathrm{~m}$ dpl. Habitat rangkong di Gunung Betung Tahura WAR merupakan hutan tropis dataran tinggi, berbukit dan lembah. Bedasarkan hasil pengamatan burung rangkong sering ditemui pada lokasi dengan kemiringan lebih dari $45^{\circ}$ dengan pohon-pohon yang tinggi $>17 \mathrm{~m}$. Burung rangkong biasa terbang tinggi di atas tajuk pohon dan hinggap di atas tajuk pepohonan.

\section{B. Keberadaan Burung Rangkong}

Bedasarkan hasil pengamatan selama penelitian menunjukkan di Gunung Betung terdapat satu spesies rangkong yaitu rangkong badak (Buceros rhinoceros). Rangkong badak memiliki paruh kuning berpangkal merah dengan tanduk berwarna merah kuning yang melengkung ke atas. Bulu didominasi warna hitam dan putih dan ekor berwarna putih mencolok dengan garis hitam lebar melintang. Jumlah individu rangkong badak yang dijumpai pada lokasi penelitian setidaknya terdapat 2 ekor, dari 66 kali perjumpaan 15 kali secara visual dan 51 kali secara audio. Satu individu rangkong selalu teramati dalam bentuk audio pada titik yang sama di lokasi ke dua dan tidak teramati secara visual. Satu individu rangkong yang lain teramati dalam bentuk audio maupun visual pada saat terbang maupun bertengger dan selalu berpindah di antara lokasi pengamatan pertama, kedua dan ketiga atau terbang jauh meninggalkan ketiga lokasi penelitian. Data frekuensi perjumpaan dengan burung rangkong tersebut disajikan dalam Tabel 1.

Tabel 1. Frekuensi perjumpaan dengan burung rangkong badak di Gunung Betung Tahura WAR.

\begin{tabular}{|c|c|c|c|c|c|c|c|c|}
\hline \multirow[t]{3}{*}{ Lokasi } & \multicolumn{6}{|c|}{ Perjumpaan } & \multicolumn{2}{|c|}{ Jumlah } \\
\hline & \multicolumn{2}{|c|}{ Pagi } & \multicolumn{2}{|c|}{ Siang } & \multicolumn{2}{|c|}{ Sore } & & \\
\hline & Visual & Audio & Visual & Audio & Visual & Audio & Visual & Audio \\
\hline Titik 1 & 3 & 2 & 2 & 1 & 4 & 1 & 9 & 4 \\
\hline Titik 2 & 0 & 17 & 5 & 7 & 0 & 14 & 5 & 38 \\
\hline Titik 3 & 1 & 4 & 0 & 4 & 0 & 1 & 1 & 9 \\
\hline Jumlah & 4 & 23 & 7 & 12 & 4 & 16 & & 66 \\
\hline
\end{tabular}

Aktivitas burung rangkong paling tinggi terjadi pada pagi hari dengan 27 kali perjumpaan diikuti 20 kali perjumpaan pada sore hari dan 19 perjumpaan pada siang hari. Tingginya aktivitas burung rangkong di pagi hari dikarenakan burung rangkong mulai aktif bersuara dan terbang di atas tajuk-tajuk pohon untuk mencari makan. Burung rangkong akan mengurangi aktivitasnya pada siang hari saat suhu udara mulai naik dan akan kembali aktif mencari makan pada sore hari saat suhu udara mulai menurun. 
Perjumpaan dengan burung rangkong pada ketiga lokasi pengamatan berturut-turut yaitu pada titik pertama 13 perjumpaan, pada titik kedua 43 perjumpaan dan pada titik ketiga sebanyak 10 perjumpaan. Berdasarkan intensitas perjumpaan pada tiga lokasi tersebut diketahui bahwa aktivitas burung rangkong tertinggi terdapat pada lokasi kedua. Tingginya perjumpaan di lokasi kedua diduga bahwa pada lokasi tersebut terdapat sarang burung rangkong. Hal ini didukung dengan adanya beberapa faktor yaitu pertama lokasi kedua ini memiliki topografi yang curam dengan karakteristik pohon-pohon yang tinggi dan besar. Kedua yaitu ditunjukkan dengan tingginya perjumpaan dengan 5 kali perjumpaan secara visual dan 38 kali secara audio. Perjumpaan dengan rangkong badak di lokasi kedua ini terjadi setiap hari selama penelitian. Ketiga yaitu aktivitas yang paling mencolok pada lokasi ke dua ini adalah bersuara. Aktivitas bersuara ini sering dilakukan dalam bentuk duet antara jantan dan betina dimana suara burung rangkong jantan lebih keras dibandingkan yang betina. Menurut MacKinnon dkk. (2010), burung rangkong merupakan jenis burung monogami yaitu hanya memiliki satu pasangan. Kebiasaan burung rangkong terbang berpasangan atau dalam kelompok kecil di atas hutan.

Ditemukannya satu spesies rangkong yaitu rangkong badak di Gunung Betung Tahura WAR menunjukkan bahwa keberadaan jenis rangkong di Gunung Betung masih lebih rendah jika dibandingkan dengan keberadaan jenis rangkong di KPHL Gunung Rajabasa. Hasil penelitian yang dilakukan di KPHL Gunung Raja Basa terdapat tiga jenis burung rangkong yaitu rangkong badak, rangkong papan (Buceros bicornis) dan kangkareng hitam (Anthracoceros malayanus) (BKSDA Lampung, 2014). Hal ini mungkin terjadi karena kondisi habitat dan tingkat gangguan terhadap burung rangkong di Gunung Betung berbeda dengan di KPHL Gunung Rajabasa. Karena menurut Hadiprakarsa dan Winarni (2007), beberapa jenis rangkong yang berukuran tubuh kecil dan bersifat teritorial seperti enggang klihingan (Anorrhinus galeritus) dan enggang jambul (Aceros comatus) memiliki tingkat kepekaan yang tinggi terhadap gangguan habitat seperti adanya perluasan tanaman perkebunan yang menyebabkan terjadinya fragmentasi habitat.

Hadiprakarsa dan Winarni (2007) menerangkan bahwa rangkong berukuran besar seperti rangkong badak, rangkong papan, rangkong gading (Buceros vigil), julang dompet (Aceros corrugatus) dan julang emas (Aceros undulatus) merupakan jenis rangkong yang mudah untuk beradaptasi dengan perubahan kondisi habitat seperti kawasan hutan dalam bentuk agroforestry. Rangkong jenis ini juga mempunyai daya jelajah yang luas sehingga tidak tergantung sepenuhnya terhadap satu petak hutan yang ada di kawasan Tahura WAR. Kurang luasnya area pengamatan selama penelitian dan daya jelajah rangkong yang tinggi maka hal tersebut mungkin menjadi salah satu penyebab tidak ditemukannya rangkong jenis lain di Gunung Betung Tahura WAR.

\section{Potensi Pohon Sarang dan Ketersediaan Pohon Pakan Burung Rangkong}

Habitat burung rangkong di Gunung Betung Tahura WAR merupakan hutan tropis dengan karakteristik pohon tinggi lebih dari $17 \mathrm{~m}$ dan berdiameter lebih dari $30 \mathrm{~cm}$. Keberadaan pohon sebagai sarang dan sumber pakan merupakan dua hal yang penting bagi kelestarian burung rangkong (Himmah, Utami dan Baskoro, 2010). Berikut spesies pohon yang berpotensi menjadi pohon pakan dan pohon sarang di Gunung Betung dalam Tabel 2.

Keberadaan pohon tinggi dan besar pada ketiga lokasi pengamatan dimanfaatkan burung rangkong untuk beraktivitas seperti bertengger, mencari makan, berlindung dan bersarang bagi burung rangkong di Gunung Betung Tahura WAR. Lokasi pengamatan pertama terdapat pohon medang (Litsea $s p$ ) famili Lauraceae merupakan pohon tertinggi dengan tinggi $27 \mathrm{~m}$ dan diameter $42 \mathrm{~cm}$ dan terdapat beberapa pohon jenis Ficus. Lokasi pengamatan kedua terdapat pohon medang yang menjadi pohon tertinggi dengan tinggi $25 \mathrm{~m}$ dengan diameter $78 \mathrm{~cm}$. Pohon tertinggi pada lokasi ketiga adalah pohon medang dengan 
tinggi $26 \mathrm{~m}$ dan diameter $37 \mathrm{~cm}$ serta terdapat beberapa jenis Ficus yang menjadi sumber pakan.

Tabel 2. Spesies pohon yang berpotensi sebagai pohon pakan dan pohon sarang.

\begin{tabular}{|c|c|c|c|c|c|c|}
\hline No & Lokasi & Nama pohon & $\begin{array}{l}\text { tinggi } \\
(\mathrm{m})\end{array}$ & $\begin{array}{c}\text { diameter } \\
(\mathrm{cm})\end{array}$ & $\begin{array}{l}\text { Potensi } \\
\text { pohon } \\
\text { pakan }\end{array}$ & $\begin{array}{c}\text { Potensi } \\
\text { pohon } \\
\text { sarang }\end{array}$ \\
\hline \multirow[t]{5}{*}{1} & Titk 1 & Medang (Litsea $s p$ ) & 27 & 42 & & \\
\hline & & Gondang (Ficus variegata) & 25 & 47 & $\sqrt{ }$ & \\
\hline & & Medang (Litsea $s p)$ & 25 & 30 & & \\
\hline & & Luwingan (Ficus hispida) & 20 & 45 & $\sqrt{ }$ & \\
\hline & & Jolang-jaling (Archidendron microcarpum) & 17 & 30 & $\sqrt{ }$ & \\
\hline \multirow[t]{4}{*}{2} & Titik 2 & Medang (Litsea $s p)$ & 25 & 78 & & $\sqrt{ }$ \\
\hline & & Medang (Litsea $s p$ ) & 24 & 40 & & \\
\hline & & Medang (Litsea $s p$ ) & 20 & 60 & & $\sqrt{ }$ \\
\hline & & Beringin (Ficus benjamina) & 19 & 56 & $\sqrt{ }$ & $\sqrt{ }$ \\
\hline \multirow[t]{7}{*}{3} & Titik 3 & Medang (Litsea $s p)$ & 26 & 37 & & \\
\hline & & Medang (Litsea $s p$ ) & 24 & 40 & & \\
\hline & & Medang kuning (Dehaasia cuneata) & 22 & 32 & & \\
\hline & & Kiarak & 20 & 32 & $\sqrt{ }$ & \\
\hline & & Sawo-sawoan (Manilkara sp) & 18 & 60 & & $\sqrt{ }$ \\
\hline & & Beringin (Ficus benjamina) & 17 & 55 & $\sqrt{ }$ & $\sqrt{ }$ \\
\hline & & Gondang (Ficus variegata) & 17 & 48 & $\sqrt{ }$ & \\
\hline
\end{tabular}

\section{Potensi Pohon Sarang}

Rachmawati, Rahayuningsih dan Kartijono (2013), menerangkan bahwa ketersediaan pohon yang berfungsi sebagai tempat bersarang merupakan hal yang terpenting bagi keberadaan rangkong untuk membesarkan anak dan mendukung eksistensinya agar tidak mengalami kepunahan. Keberadaan pohon besar yang berpotensi menjadi sarang burung rangkong di Gunung Betung sudah jarang ditemukan. Pohon medang merupakan pohon terbesar yang ditemui di lokasi penelitian dengan diameter $>65 \mathrm{~cm}$. Adapun pohon-pohon lain yang memiliki diameter cukup besar yakni sawo-sawoan (Manilkara sp), beringin (Ficus benjamina), dan gondang (Ficus variegata).

BKSDA Lampung (2014) menyatakan, karakteristik pohon yang diminati burung rangkong untuk bersarang adalah pohon berdiameter besar. Pohon besar (diameter setinggi dada $>65 \mathrm{~cm}$ ) diperkirakan memiliki potensi sebagai pohon sarang. Akan tetapi, tidak menutup kemungkinan burung rangkong juga dapat bersarang pada pohon yang memiliki ukuran diameter di bawah $65 \mathrm{~cm}$ karena selain ukuran diameter pohon yang besar, karakteristik pohon sarang adalah memiliki lubang alami untuk dijadikan sarang. Pohon yang tinggi dan memiliki beberapa percabangan juga diminati untuk menjadi tempat bertengger atau sekedar beristirahat (BKSDA Lampung, 2014).

Burung rangkong yang dijumpai di Gunung Betung sering beraktivitas di pohon besar seperti jenis Ficus dan Litsea sp. yang banyak dijumpai pada lokasi penelitian. Pohon-pohon tersebut dimanfaatkan sebagai tempat mencari makan, bertengger, berlindung dan bersarang bagi burung rangkong. Menurut UPTD Tahura WAR (2009), terdapat beberapa jenis pohon yang terdapat di kawasan Tahura WAR terutama pada hutan primer antara lain jenis merawan (Hopea mangarawan), medang (Litsea sp), rasamala (Altingia excelsa), bayur (Pterospermum sp), jabon (Antocepalus cadamba), cempaka (Michelia sp), pulai (Alstonia scholaris) dan lain-lain. Rachmawati dkk. (2013), menyatakan bahwa jenis Litsea sp. merupakan pohon yang berpotensi sebagai sarang bagi burung rangkong. 


\section{Ketersediaan Sumber Pakan}

Ketersediaan pakan dalam suatu tipe habitat merupakan salah satu faktor yang mempengaruhi keberadaan burung rangkong (Mangangantung, Deidy, Saroyo dan Maabaut, 2015). Ketersediaan sumber pakan bagi burung rangkong pada lokasi penelitian di Gunung Betung didukung dengan adanya beberapa jenis Ficus yang menjadi sumber pakan utamanya yakni gondang, luwingan dan beringin. Indriyanto (2006), hutan alami pada kawasan Tahura WAR pada umumnya memiliki kerapatan 96 individu/ha dengan spesies dominan yaitu benying (Ficus fistulosa), gondang (Ficus variegata) dan lamerang (Ficus fulva). Keberadaan jenis Ficus ini menjadi faktor penting untuk mendukung ketersediaan sumber pakan bagi burung rangkong.

Bedasarkan informasi dari masyarakat burung rangkong di Gunung Betung juga mengkonsumsi buah selain dari pohon Ficus yaitu buah kiarak, jaling (Archidendron microcarpum) dan buah-buahan dari jenis lain. Afandi dan Winarni (2007) menyatakan bahwa rangkong badak memiliki alternatif jenis buah pakan dari buah non Ficus dan serangga. Rangkong badak sama sekali tidak memperlihatkan preferensi tertentu terhadap karakter buah baik berat, panjang, lebar, dan ukuran buah.

Rangkong badak menghabiskan waktunya di bagian atas tajuk hutan dengan makanan utama buah-buahan, serangga, reptil kecil, hewan pengerat, dan burung-burung kecil (Widjojo, 2011). Oleh karena itu, peran ekologi burung rangkong sebagai pemancaran biji sangat penting bagi keberlanjutan dan penyeimbang ekosistem hutan. Biji dari buah yang dikonsumsi burung rangkong yang tidak hancur ketika dicerna akan tumbuh dan berkembang dan menjadi individu baru. Hubungan timbal balik antara tumbuhan sebagai produsen dengan konsumen yaitu burung rangkong memiliki keterkaitan yang erat sehingga jika salah satunya mengalami kepunahan akan berpengaruh terhadap keberlanjutan ekosistem hutan (Mangangantung dkk., 2015).

\section{Ancaman Terhadap Burung Rangkong dan Habitatnya}

Ancaman terhadap burung rangkong di Gunung Betung terjadi secara tidak langsung terhadap burung rangkong. Akan tetapi, ancaman tersebut terjadi pada habitat burung rangkong dengan banyaknya aktivitas manusia seperti perusakan hutan meliputi kegiatan pencarian kayu bakar, pengambilan rebung bambu, camping dan perburuan liar seperti babi hutan, primata dan burung-burung kecil. Ancaman juga terjadi dengan adanya perluasan tanaman perkebunan seperti kopi, kakao dan karet. Hal tersebut dapat merusak kestabilan ekosistem yang ada di dalam hutan dan menjadi ancaman bagi keberadaan burung rangkong di Gunung Betung karena kondisi habitat yang terganggu. Hadiprakarsa dan Winarni (2007) menyatakan bahwa semua petak hutan di luar kawasan taman nasional mengalami ancaman yang cukup mengkhawatirkan, khususnya petak hutan berukuran kecil mengalami tekanan hebat berupa pembalakan hutan dan perubahan penggunaan lahan menjadi lahan pertanian atau perkebunan, khususnya kopi.

Beberapa masyarakat di sekitar Gunung Betung menyatakan bahwa burung rangkong sering melintas dan bertengger di pepohonan dalam kebun mereka sehingga mereka nampak terbiasa dengan kehadiran burung rangkong. Menurut Hadiprakarsa dan Winarni (2007), selain kawasan hutan primer, kawasan penyangga berupa daerah agroforestry dimanfaatkan oleh burung rangkong dalam mencari pakan alternatif. Masyarakat menyadari bahwa burung rangkong merupakan burung yang langka dan dilindungi oleh pemerintah. Oleh karena itu, mereka enggan melakukan perburuaan terhadap burung tersebut mengingat resiko hukuman yang akan di tanggung jika mereka tertangkap melakukan perburuan terhadap burung tersebut. Burung rangkong badak merupakan satwa yang dilindungi oleh UU No. 7 tahun 1999 tentang Pengawetan Tumbuhan dan Satwa. IUCN memasukkan satwa yang termasuk spesies yang hampir mengalami kelangkaan. 


\section{KESIMPULAN}

\section{A. Kesimpulan}

Bedasarkan penelitian keberadaan burung rangkong di Gunung Betung Tahura Wan Abdul Rachman yang telah dilakukan di peroleh kesimpulan sebagai berikut:

1. Terdapat satu spesies rangkong di Gunung Betung Tahura WAR yakni rangkong badak (Buceros rhinoceros).

2. Potensi pohon sarang bagi burung rangkong di Gunung Betung terdapat Pohon medang (Litsea $s p$ ) dengan diameter $>65 \mathrm{~cm}$. Adapun pohon-pohon lain yang memiliki diameter cukup besar yakni sawo-sawoan, beringin, dan gondang.

3. Ketersediaan sumber pakan bagi burung rangkong di Gunung Betung didukung dengan adanya beberapa jenis Ficus yang menjadi sumber pakan utamanya yakni gondang, luwingan dan beringin.

4. Ancaman dan gangguan terhadap burung rangkong dan habitatnya yakni adanya aktivitas manusia seperti perusakan hutan dan perluasan tanaman perkebunan kopi, kakao dan karet.

\section{DAFTAR PUSTAKA}

Affandi, F. R. dan N. L. Winarni. 2007. Prefrensi dan interaksi burung rangkong terhadap ketersediaan buah ara (Ficus spp) di Way Cungguk, Taman Nasional Bukit Barisan Selatan, Lampung. Jurnal Indonesian Ornithologists' Union (IdOU). 5 (1):85-92.

BKSDA Lampung. Inventarisasi rangkong (Bucerotidae) di Kesatuan Pengelolaan Hutan Lindung (KPHL) Gunung Rajabasa. 2014. Diakses 18 Januari 2015. (http://www.krakatau.co.id).

Menyusuri kepakan sayap si penjaga hutan. 2014. Diakses 18 Januari 2015. (http://www.krakatau.co.id).

Hadiprakarsa, Y. dan N. L. Winarni. 2007. Fragmentasi hutan di Lampung, Sumatera vs burung rangkong: Mampukah burung rangkong bertahan hidup? Jurnal Indonesian Ornithologists' Union (IdOU). 5 (1):94-102.

Himmah, I., S. Utami. dan K. Baskoro. 2010. Struktur dan komposisi vegetasi habitat julang emas (Aceros undulatus) di Gunung Unggaran Jawa Tengah. Jurnal Sains dan Matematika (JSM). 18 (3):104-110.

Indriyanto. 2006. Ekologi Hutan. Buku. Bumi Aksara. Jakarta. 209 p.

MacKinnon, J., K. Philipps dan B. Van Balen. 2010. Burung di Sumatera, Jawa, Bali dan Kalimantan (termasuk Sabah, Serawak, dan Brunei Darussalam). Buku. PuslitbangBiologi. Jakarta. 521 p.

Mangangantung, B., D. Y. Katili., Saroyo dan Pience V. Maabuat. 2015. Densitas dan jenis pakan burung rangkong (Rhyticeros cassidix) di Cagar Alam Tangkoko Batuangus. Jurnal MIPA UNSRAT Online. 4 (1):88-92.

Rachmawati, Y., M. Rahayuningsih dan N. E. Kartijono. 2013. Populasi julang emas (Aceros undulatus) di Gunung Ungaran Jawa Tengah. Unnes Journal of Life Science. 2 (1):43-49.

Republik Indonesia. 1990. Undang-undang No. 5 Tahun 1990 Tentang Konservasi Sumber Daya Alam Hayati dan Ekosistemnya. Lembaran Negara RI Tahun 1990 No. 49. Sekretariat Kabinet RI. Jakarta. 13 p.

Republik Indonesia. 1999. Peraturan Pemerintah No. 7 Tahun 1999 Tentang Pengawetan Jenis Tumbuhan dan Satwa. Lembaran Negara RI Tahun 1999, No. 14. Sekretariat Kabinet RI. Jakarta. 10 p. 
Sukmantoro, W., M. Irham, W. Novarino., F. Hasudungan., N. Kemp. dan M. Muchtar. 2007. Daftar Burung Indonesia no. 2. Buku. Indonesian Ornithologists' Union. Bogor. 157 p.

UPTD Tahura WAR. 2009. Buku Informasi Tahura. Buku. Dinas Kehutanan Provinsi Lampung. Bandar Lampung. 43 p.

Widjojo, N. Rangkong badak. 2011. Factsheet Yayasan WWF Indonesia. Diakses tanggal 2 Januari 2015. (http://awsassets.wwf.or.id). 